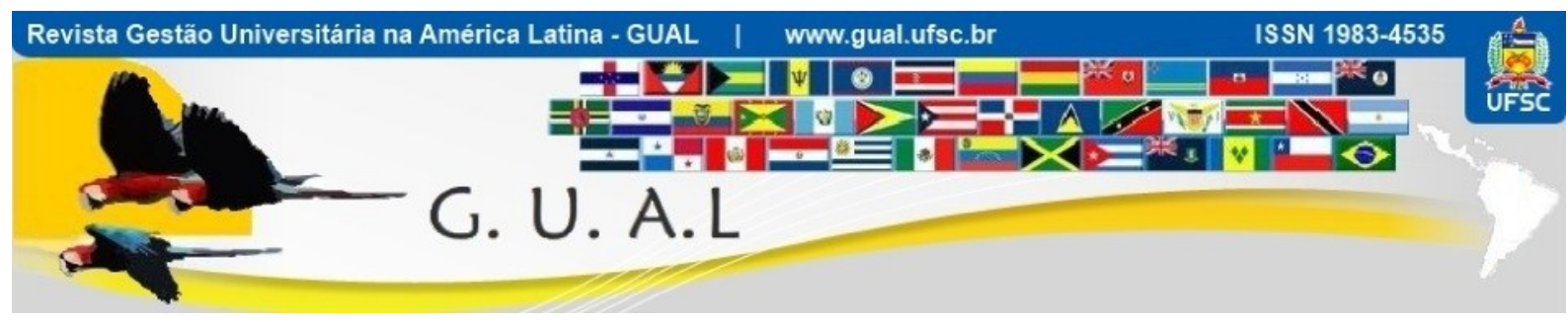

DOI: http://dx.doi.org/10.5007/1983-4535.2012v5n2p174

\title{
A RELAÇÃO DE VALORES DE POTENCIAIS CONSUMIDORES DE CURSOS DE GRADUAÇÃO
}

\section{THE RELATIONSHIP VALUES OF POTENTIAL CONSUMERS OF UNDERGRADUATE COURSES}

Samuel Carvalho De Benedicto, Doutor

Pontifícia Universidade Católica de Campinas - PUC/Campinas sdebenedicto@,bol.com.br

Aline Michelli Penido da Silva, Mestre Fundação Educacional de Oliveira - FEOL alinemichelli@hotmail.com

Luiz Henrique de Barros Vilas Boas, Doutor Universidade Federal de Alfenas - UNIFAL luiz.vilasboas@unifal-mg.edu.br

Cândido Ferreira da Silva Filho, Doutor Pontifícia Universidade Católica de Campinas - PUC/Campinas candidofilho@puc-campinas.edu.br

Recebido em 21/outubro/2011

Aprovado em 09/abril/2012

Sistema de Avaliação: Double Blind Review

Esta obra está sob uma Licença Creative Commons Atribuição-Uso. 


\begin{abstract}
RESUMO
Atualmente as Instituições de Ensino Superior (IES) enfrentam grande competitividade e, por isso, buscam um novo posicionamento no mercado. A compreensão do perfil do consumidor permite o desenvolvimento de estratégias de posicionamento para novos produtos/serviços. Para tanto, é necessário compreender as variáveis que precisam ser aperfeiçoadas a fim de melhorar a imagem corporativa da organização e a satisfação dos ingressantes e dos alunos com os serviços educacionais oferecidos. Assim, esta pesquisa tem como objetivo identificar a relação de valores de potenciais consumidores de cursos de graduação, quando da escolha de uma IES. Foram realizadas entrevistas em profundidade utilizando-se a técnica qualitativa laddering, que faz uso dos pressupostos teóricos da cadeia de meios e fins. Foi construído um Mapa Hierárquico de Valor (MHV), o qual permite identificar as cadeias dominantes que influenciam o comportamento do consumidor em sua decisão de compra. Os resultados mostram a preocupação dos consumidores com IES que apresentem um conjunto de atributos essenciais que lhes permitam ocupar um lugar no mercado de trabalho e alcançar uma gama de aspirações pessoais. Os clientes/consumidores pesquisados almejam IES que tenham reconhecimento da sociedade, professores qualificados, ensino de qualidade e aulas práticas em laboratórios especializados. Tais atributos levam a diversas consequências desejáveis aos consumidores dos serviços educacionais no ensino superior: a ampliação do conhecimento do estudante, o aumento das chances de conseguir um emprego, a segurança no exercício da profissão e a conquista da tão sonhada independência financeira. Tais atributos e consequências se encontram ligados a diversos valores, tais como prazer, segurança, realização pessoal, felicidade, solidariedade e independência/liberdade.
\end{abstract}

Palavras-chave: Instituições de Ensino Superior. Cadeia de meios e fins. Laddering. Valores. Comportamento do consumidor.

\begin{abstract}
Nowadays, the Higher Learning Institutions (IES) face great competitivity, they search a new positioning on market. The understanding of the consumer profile enables the development of positioning strategies for new products/services. Thus, it is necessary to understand the variables which need to be improved in order to make the corporate image of the organization and the satisfaction of the entrant and students with the offered education services better. This work was intended to identify the relationship of the values of potential consumers of undergraduate courses when of the choice of an IES. In-depth interviews utilizing the qualitative technique laddering, were performed which make use of the theoretical presupposed ones of the mean and purpose chains. A hierarquical value map (MHV) was constructed, which allows to identify the dominant chains which influence the consumer's behavior in his purchasing decision. The results show the consumers' concern about the IES which present a set of essential attributes which allow a place in the labor market and reach a range of personal aspirations. The clients/consumers investigated long for IES which possess: recognition of the society, qualified professors; high quality teaching; practical classes in specialized laboratories. Such attributes lead to diverse desirable consequences to the consumers of the education services in higher learning: the broadening of the knowledge of the student; the increase of the chances to get a job; the safety in profession practice; the conquest of the so-dreamt financial independence. Such attributes and consequences are linked to several values such as pleasure, safety, self-fulfillment, happiness, solidarity and independence/liberty.
\end{abstract}

Keywords: Higher learning institution. Means-end chain. Laddering. Values. Consumer behavior. 


\section{INTRODUÇÃO}

Os desafios que caracterizam o ambiente em que as Instituições de Ensino Superior (IES) estão operando têm provocado modificações no sistema educacional do país. Há um crescimento exacerbado no número de instituições ofertando produtos e serviços no ensino superior. Algumas delas passam a adotar comportamentos agressivos e pouco éticos, determinando padrões de concorrência predatória. Soma-se a isso a proposição feita por Estados Unidos, Nova Zelândia e Austrália de inclusão do ensino superior entre os serviços comerciais listados no Acordo Geral sobre o Comércio de Serviços (GATS), da Organização Mundial do Comércio - que introduz, pela primeira vez, a educação como um produto que pode ser comercializado em todo o mundo. Entretanto, mesmo diante das constantes mudanças nas características do mercado, as IES ainda são limitadas na compreensão da satisfação das necessidades de seus clientes (PIÑOL, 2008; OECD, 2008).

Essa atual expansão no consumo de produtos e serviços educacionais demanda estudos que levem à compreensão das necessidades, desejos e comportamento dos consumidores desse importante segmento da sociedade (SGUISSARDI, 2008). Uma das abordagens de estudo do comportamento do consumidor, a teoria de meios e fins (GUTMAN, 1982), tem como base os valores pessoais que conduzem as escolhas de compra dos consumidores. A teoria de meios e fins auxilia o pesquisador a desvendar quais características de produtos e/ou serviços são capazes de conduzir o consumidor ao alcance de seus valores pessoais, ou seja, qual seria a representação semântica dessas características em relação à percepção desse consumidor.

Para compreender os fatores que influenciam as motivações de compra de produtos e serviços educacionais, é necessário definir como funciona esse comportamento em termos de valores pessoais, que é a ótica de análise utilizada neste estudo. A teoria de meios e fins faz uso de uma técnica denominada laddering (REYNOLDS; GUTMAN, 1988), que auxilia na identificação dos atributos (características) do produto/serviço, de seus benefícios e dos valores entendidos como crenças e cognições do consumidor. A técnica laddering vem sendo utilizada nas áreas de administração e marketing para investigar opiniões, atitudes e crenças de indivíduos, sendo bastante recomendada em pesquisas que abordam o valor para o cliente (VELUDO-DE-OLIVEIRA; IKEDA, 2006a, 2006b; VILAS BOAS, 2007; PIMENTA; VILAS BOAS, 2008). 
Fazendo uso da teoria de meios e fins e da técnica laddering, esta pesquisa, de natureza qualitativa, tem como objetivo geral identificar a relação de valores de potenciais consumidores de cursos de graduação - alunos do terceiro ano do Ensino Médio - quando da escolha de uma Instituição de Ensino Superior (IES). De modo específico pretende-se: (i) identificar os atributos de maior importância e as consequências (benefícios) que caracterizam a tomada de decisão com relação à escolha da IES; (ii) identificar os valores; (iii) construir um Mapa Hierárquico de Valores que represente a estrutura cognitiva desses consumidores.

Pretende-se, portanto, revelar quais são os atributos, consequências e valores desejados por esse consumidor e qual a percepção deste em termos de significado cognitivo. De acordo com Schwartz (1992), um mesmo atributo pode ser capaz de conduzir o consumidor a diferentes valores. Para tanto, é necessário observar a quantidade de relações entre um elemento e outro, evidenciando as relações entre eles.

Para analisar tais relacionamentos de modo gráfico, foi construído um mapa hierárquico de valor, que permite observar as diversas cadeias formadas, sendo que as cadeias dominantes são aquelas que influenciam o comportamento do consumidor em questão.

A pesquisa de valores pessoais em marketing tem recentemente recebido muita atenção tanto dos acadêmicos quanto dos profissionais. Essa classificação por perfil do consumidor e sua relação com os produtos/serviços oferece potencial não apenas para se entender o posicionamento "cognitivo" dos atuais produtos, mas também permite o desenvolvimento de estratégias de posicionamento para novos produtos/serviços. Do ponto de vista do marketing estratégico, conhecer os valores dos consumidores é fundamental. Essas evidências poderão auxiliar o novo posicionamento da IES no mercado frente ao cenário competitivo que estão enfrentando atualmente, na medida em que indicam as variáveis que precisam ser aperfeiçoadas a fim de se melhorar a imagem corporativa da organização e a satisfação dos ingressantes e dos alunos com os serviços educacionais oferecidos.

A estrutura deste trabalho consiste em um referencial teórico, que aborda as IES e o mercado no contexto atual, o comportamento do consumidor com base em valores, a teoria da cadeia de meios e fins e a técnica laddering. Na sequência são apresentados os aspectos metodológicos envolvidos na coleta e na análise de dados. Por fim, são discutidos os resultados da pesquisa de campo e são apresentadas as considerações finais. 


\section{INSTITUIÇÕES DE ENSINO SUPERIOR E MERCADO}

Durante o Período Imperial, todo o ensino superior brasileiro era estatal e centralmente controlado. Ao adaptar o formato do Estado à federação dos poderes regionais, a República quebrou esse padrão, destravando as amarras que impediam a expansão do ensino superior nas províncias (CUNHA, 2004).

Desde a década de 1960, o sistema de ensino superior brasileiro vem enfrentando um longo período de transformações, em que se testemunhou a rápida expansão do setor, acompanhada pela diferenciação das instituições de ensino para novas formas e pelos reflexos da chamada revolução do conhecimento (ANDRADE FILHO, 2000).

Nas duas últimas décadas o número de instituições privadas aumentou consideravelmente no Brasil, em especial as universidades e os centros universitários, o que resultou na ampliação do alunado abrangido pelo setor. Atualmente, o crescimento anual de IES privadas no Brasil gira em torno de 3\% a 4\% (INEP, 2009).

Essa movimentação no mercado de ensino acirrou a concorrência entre as IES privadas e públicas e a busca de potenciais alunos tem se evidenciado não apenas nos meios comunicativos, mas na flexibilização dos processos seletivos de ingresso de alunos nessas instituições (PIÑOL, 2008). Nesse sentido, Silva e Anastácio (2005) argumentam que o aumento da concorrência, com a abertura de novas instituições e cursos e a oferta crescente de vagas, sem o aumento paralelo da demanda, está fazendo com que as IES passem por dificuldades crescentes. Assim, o ensino superior deixou de ser um mercado atraente, principalmente nas grandes cidades.

Além dos aspectos relacionados às políticas educacionais do país, as IES atravessam um período de significativas mudanças no seu ambiente externo, envolvendo a globalização da economia, o incremento significativo de novas tecnologias e novas demandas sociais. A isso somam-se a crise do emprego, a nova LDB (Lei de Diretrizes e Bases da Educação Nacional), a modificação no perfil das carreiras tradicionais e a diminuição significativa dos recursos governamentais para ciência e tecnologia. Diante desse panorama, as IES privadas, e até algumas públicas, já adotam posturas mais arrojadas, ampliando as suas abrangências geográficas e propondo novos cursos e métodos modernos de ensino. Assim, estabelece-se a competição entre as organizações do setor, seja na busca por alunos, seja por recursos a serem obtidos na iniciativa privada (pela prestação de serviços) e pelas verbas de pesquisa junto aos órgãos governamentais (BORENSTEIN, 2008). 
Entretanto, as raízes dessas transformações se encontram além das fronteiras nacionais. Uma análise comparativa possibilita concluir que o cenário atual do Brasil não foge aos parâmetros internacionais. Em diferentes nações, as novas dinâmicas do segmento educacional obrigam as IES a se adaptarem, não apenas no que se refere à ação do Estado enquanto "modelador", "regulamentador" e "fiscalizador", mas também no que se refere à dinâmica do mercado onde estão inseridas (SGUISSARDI, 2008).

Diante desse cenário, a OECD (2008) publicou o relatório "Tertiary Education for the Knowledge Society", que aborda temas como tendências e mudanças na educação superior, governança, novos provedores, internacionalização, financiamento, mercado educacional, papel do Estado, entre outros. É consenso que há um processo de mercantilização da educação, impulsionado pelos novos provedores internacionais e pelo crescimento dos grandes grupos educacionais. No caso do Brasil, pode-se afirmar que existe uma situação de "quase mercado", em função das políticas do Estado e dos grandes grupos educacionais de origem nacional e internacional já estabelecidos ou em processo de estabelecimento.

Ao tratar dessa temática, Brunner e Uribe (2007) afirmam que é necessário aprender a conviver e a enfrentar os desafios de um processo de mercantilização da educação superior. Em uma economia de mercado educacional, as IES estão em permanente competição por prestígio. Há competição por financiamento, alunos, professores, venda de serviços, boas avaliações de organizações públicas e privadas, publicações científicas e impacto nas ações sociais. Os rankings estão cada vez mais presentes no cotidiano de todos e servem de parâmetro para os clientes no momento da escolha da instituição.

No Brasil, grandes grupos educacionais (a exemplo de Anhanguera Educacional, Estácio Participações, Veris Educacional e Kroton Educacional) tendem a se consolidar e a se expandir em função dos recursos financeiros e do modelo de gestão que possuem. Nos próximos anos, provavelmente, o mercado estará dividido entre os grandes grupos de educação (nacionais e internacionais). Borenstein (2008) afirma que, diante desse cenário competitivo, a manutenção e o futuro das IES serão influenciados pela forma como cada organização se comporta no novo ambiente. A implementação de objetivos e estratégias competitivos, pautados numa visão mercadológica, certamente definirá o futuro dessas IES.

O marketing é uma atividade central das instituições modernas. As instituições educacionais tornaram-se realmente conscientes dessa atividade quando seus mercados passaram a sofrer mudanças. Com o aumento da concorrência, o marketing em IES convertese em uma ferramenta necessária para diferenciar os serviços, atrair e manter os alunos, seja 
através da criação de valor da marca, confirmando a qualidade da instituição ou do sistema de ensino, entre outros, seja direcionando a utilização de métodos da abordagem mercadológica para a conquista de novos clientes e a manutenção dos clientes atuais (KOTLER; FOX, 1994; PIÑOL, 2008).

É inegável que o marketing é essencial para a sobrevivência da maioria das empresas, como também das IES. Deve-se considerar ainda que, se a razão de ser da maioria das empresas são seus clientes, a razão de existir das instituições de ensino são seus alunos. Sem eles, as escolas fechariam suas portas, principalmente num ambiente fortemente competitivo como o atual. Nesse sentido, é preciso estudar as necessidades mutantes desse mercado, a partir de vários pontos de vista, tais como as expectativas das empresas no mercado de trabalho e as aspirações particulares dos ingressantes (sendo este último o objeto de análise deste estudo).

Estudar essa vertente é importante, pois os pregressos necessitam de um referencial ao qual se ancorar no processo de escolha de uma IES e durante a realização dos seus respectivos cursos. Os egressos das IES levam consigo o nome da instituição; passam a atuar no mercado e a serem reconhecidos e associados a estas pela sociedade. Representando "microrretratos" da IES responsável pela sua formação, portanto, os egressos são responsáveis pela propagação da imagem institucional, que pode ser favorável ou desfavorável, tanto em função do desempenho do aluno no mercado como pela imagem já formada da IES, oriunda de outras interações positivas ou negativas desta com a sociedade (PIÑOL, 2008). Tendo isso em vista, torna-se importante conhecer as aspirações particulares dos ingressantes - e, de acordo com Reynolds e Gutman (1988) e Baker, Thompson e Engelken (2004), uma alternativa para isso é conhecer os valores pessoais do consumidor.

De acordo com os autores, dentro da perspectiva da cadeia de meios e fins, a laddering permite revelar a estrutura cognitiva dos indivíduos. A premissa central na técnica laddering é que os níveis inferiores de abstração afetam os níveis mais elevados, ou seja, atributos dos produtos geram consequências desejáveis (benefícios) e estes, por sua vez, levam à satisfação dos valores pessoais.

\section{TEORIA DE MEIOS E FINS E LADDERING}

A teoria da cadeia de meios e fins tem sido utilizada em diversas pesquisas que procuram identificar atributos (características) de produtos/serviços capazes de alcançar os 
valores pessoais. Os atributos dos produtos são meios para alcançar um fim, que são os valores (IKEDA; VELUDO-DE-OLIVEIRA, 2004).

Para Gutman (1982), meios são objetos (produtos) ou atividades através dos(as) quais se satisfaz um estado existencial representado pelos valores (fins). O modelo de cadeias de meios e fins (ou MEC, do inglês means-end chain) descreve essa relação entre os meios e os fins. Tal teoria visa explicar como um produto ou serviço facilita o alcance de estados finais desejados.

As cadeias de meios e fins presumem uma hierarquia de níveis de metas (HUFFMAN, RATNESHWAR; MICK, 2000). O consumidor atua dentro de uma estrutura hierárquica com três níveis ligados entre si. Os níveis hierárquicos relacionados pela teoria de cadeias de meios e fins são os atributos dos produtos, as consequências do consumo e os valores pessoais (GUTMAN, 1982). Olson e Reynolds (1983) propõem um modelo ampliado e recomendam que os atributos sejam subdivididos em concretos e abstratos, as consequências em funcionais e psicológicas e os valores pessoais em instrumentais e terminais, totalizando seis níveis, conforme exposto na figura 1.

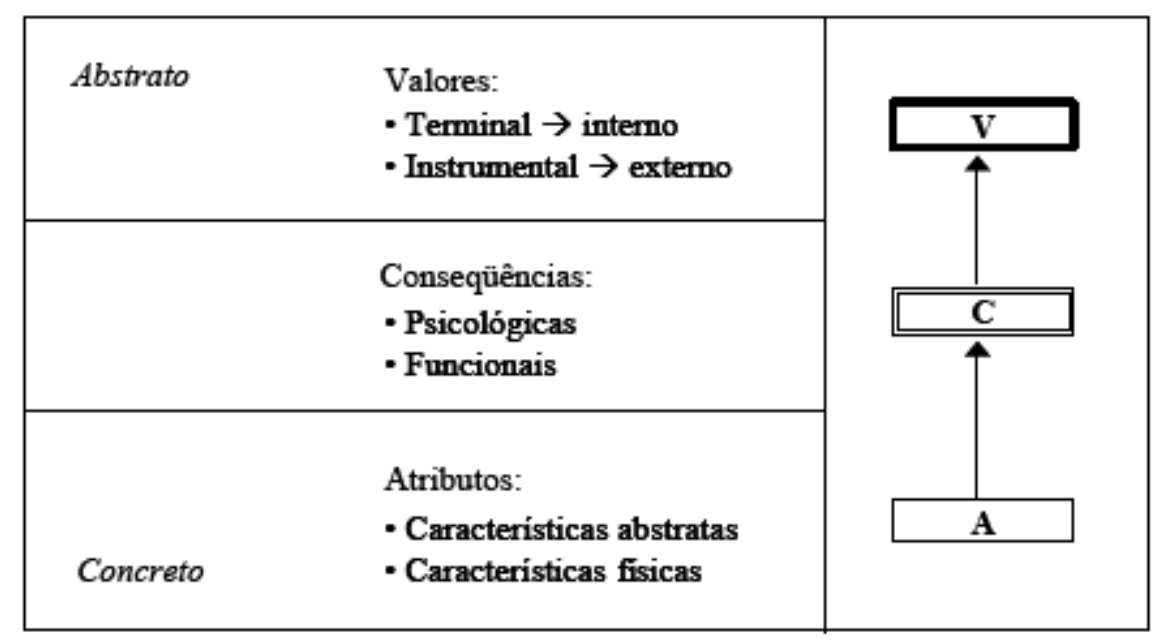

Figura 1 Níveis de abstração da cadeia de meios e fins ampliada Fonte: Vallete-Florence e Rapachi (1991).

Os atributos são as características ou aspectos dos produtos ou serviços que podem ser classificados em intrínsecos (durabilidade, odor) e extrínsecos (preço, marca). As consequências, por sua vez, podem ser funcionais (atuam no consumidor ao consumir o produto) e psicossociais (produzidas pelas consequências funcionais). (VALLETEFLORENCE; RAPACHI, 1991; VELUDO-DE-OLIVEIRA; IKEDA, 2006a). 
O valor, nas palavras de Rokeach (1973, p. 5), é "uma crença duradoura em que um específico modo de conduta ou estado final de existência é pessoalmente ou socialmente preferível a um modo oposto ou inverso de conduta de um estado final de existência". Os valores podem ser classificados como instrumentais (mostram se o comportamento do consumidor está alinhado com o resultado que ele pretende de uma ação) e terminais (englobam os estados desejados pelo consumidor como conduta de vida).

Através do MEC é possível traçar uma linha lógica hierárquica, identificando-se atributos do produto, as consequências de seu uso e os valores individuais, formando uma ladder (VELUDO-DE-OLIVEIRA; CAMPOMAR, 2006).

A laddering é "uma técnica de entrevista em profundidade, individual, usada para compreender como os clientes traduzem o atributo de produtos em associações com significados a respeito de si mesmos" (REYNOLDS; GUTMAN, 1988, p. 12). A laddering surgiu com o intuito de tentar compreender o significado de certos comportamentos (IKEDA; VELUDO-DE-OLIVEIRA, 2004). Tal técnica, por ser essencialmente qualitativa, exige que os respondentes façam abstrações, buscando acessar os sistemas de significados pessoais de indivíduos.

Segundo Gutman (1991) a técnica de escalonamento ou laddering tem como principal objetivo especificar o conteúdo do discurso e descrever a estrutura cognitiva dos consumidores acerca de seu próprio comportamento e dos outros.

A laddering pressupõe que os consumidores compram determinados produtos ou serviços por acreditarem que poderão obter algo no âmbito pessoal (SERRALVO; IGNACIO, 2004). Ao valorizarem um determinado atributo em um produto ou serviço, o consumidor acredita que obterá determinados benefícios e que estes o levarão a alcançar determinados valores.

O desenvolvimento da laddering passa por uma pesquisa rigorosa constituída pela identificação de atributos do produto, pela condução das entrevistas em profundidade e pela análise dos resultados (GUTMAN, 1991; REYNOLDS; GUTMAN, 1988).

Após a exposição dos atributos (características) do produto, que podem ser concretos ou abstratos, o pesquisador procura interagir com o pesquisado a fim de identificar consequências e valores pessoais. Uma das técnicas para a identificação das consequências e atributos é ter como referência a pergunta “Por que é importante?". 
Identificados os atributos, consequências e valores das entrevistas através da análise de conteúdo, o passo seguinte é agrupar aqueles que mais se assemelham e codificar os elementos em ordem crescente.

Com os elementos agrupados e em ordem, o próximo passo é construir uma matriz de implicação, na qual os elementos agrupados são alocados através de seus códigos, nas linhas e colunas de uma tabela numérica, formando uma matriz (IKEDA; VELUDO-DE-OLIVEIRA, 2004). A matriz de implicação ajuda na construção do mapa hierárquico de valores, o qual constitui a fase final da laddering.

O mapa hierárquico de valores relaciona as ligações entre atributos, consequências e valores, o que facilita a interpretação da cadeia de meios e fins.

Vale ressaltar que nem todas as entrevistas chegam a constituir uma cadeia de meios e fins, o que, segundo Reynolds e Gutman (1988), é normal desde que estas não ultrapassem um quarto das entrevistas.

\section{VALORES PARA O CLIENTE/CONSUMIDOR (CUSTOMER VALUE)}

Woodruff (1997) estudou uma série de definições propostas por diversos autores sobre a noção de valor para o cliente. Entre os aspectos comuns das definições se encontram três componentes importantes: (i) o valor para o cliente relaciona-se ao uso de algum produto (bem físico ou serviço); (ii) o valor é algo percebido pelo cliente, em vez de objetivamente determinado pelo fornecedor; (iii) o valor para o cliente envolve a diferença entre o que ele recebe (qualidade, benefícios, valia, utilidade) e o que ele abre mão para adquirir e usar um produto (preço, sacrifícios). Na visão do autor, o valor para o cliente se encontra relacionado aos valores pessoais.

Os valores pessoais são crenças intrínsecas, duradouras e relativamente estáveis na vida de um indivíduo. Essas crenças são representações mentais de necessidade e são utilizadas pelos indivíduos como base geral para a resolução de conflitos e decisões, pois elas determinam, regulam e modificam relações entre indivíduos, organizações e sociedades. Além disso, elas ajudam a explicar por que os consumidores tomam decisões diferentes e representam as crenças do consumidor sobre a vida e o comportamento aceitável. A natureza duradoura dos valores e seu papel central na estrutura da personalidade os fazem ser aplicados para a compreensão de muitas situações de consumo, incluindo a escolha de produtos/serviços, a escolha de marcas e a segmentação de mercado (VELUDO-DEOLIVEIRA; IKEDA, 2005; TAMAYO, 2007). 
De acordo com Woodruff (1997), existe uma hierarquia de valores para os clientes, conforme representado na figura 2.

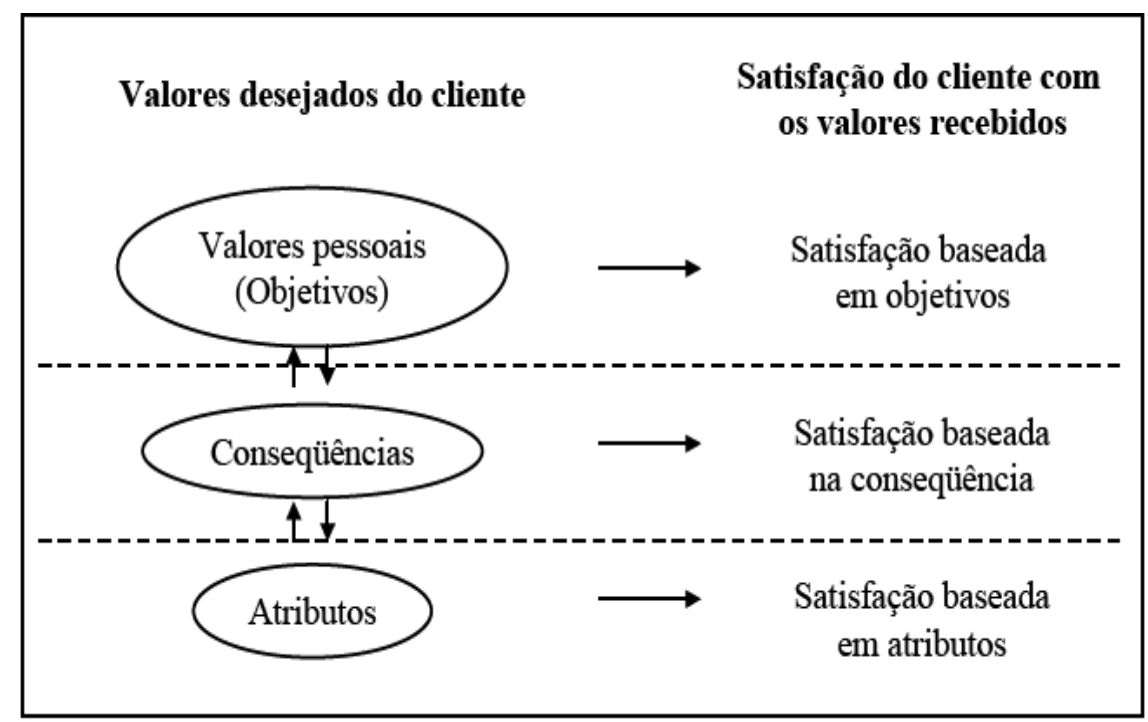

Figura 2 Hierarquia de valores para o cliente Fonte: Woodruff (1997).

Rokeach (1973) criou uma escala utilizada por muitos autores para mensurar valores, conforme exposto no quadro 1. Para o autor, os valores dizem respeito tanto às metas quanto à maneira de comportar-se para se obtê-las.

\begin{tabular}{|l|l|}
\hline $\begin{array}{c}\text { Terminal } \\
\text { Estados Finais Desejáveis }\end{array}$ & \multicolumn{1}{|c|}{$\begin{array}{c}\text { Instrumental } \\
\text { Modos de Conduta }\end{array}$} \\
\hline Uma vida confortável & Ambicioso \\
Uma vida excitante & Mente aberta \\
Um sentimento de realização & Capaz \\
Um mundo em paz & Alegre \\
Um mundo de beleza & Limpo \\
Igualdade & Corajoso \\
Segurança familiar & Magnânimo \\
Liberdade & Prestativo \\
Felicidade & Honesto \\
Harmoniza interior & Imaginativo \\
Amor maduro & Independente \\
Segurança nacional & Intelectual \\
\hline
\end{tabular}

Quadro 1 Escala de valores de Rokeach Fonte: Rokeach (1973).

Kahle, Beatty e Homer (1986) realizaram uma pesquisa na Michigan University, na qual buscaram identificar as relações existentes entre o comportamento cotidiano do cliente e seus valores pessoais. De acordo com os autores, os clientes buscam: autorrespeito, 
autorrealização, segurança, sensação de pertencimento, excitação, sentimento de realização (dever cumprido), diversão, respeito, relações calorosas com os outros, dentre outros.

Por sua vez, na escala de Schwartz (1992) representada no quadro 2, os valores correspondem a objetivos que atendem ao interesse de indivíduos ou grupos. Segundo a visão do autor, as motivações ou tipos de valor são os princípios orientadores na vida dos consumidores.

No modelo de Schwartz (1992), os valores pessoais podem ser classificados em quatro dimensões: abertura à mudança, autotranscendência, autoaprimoramento e conservadorismo. Essas dimensões permitem agrupar diferentes tipos de valores que influenciam o comportamento das pessoas. Esses tipos de valores, ou domínios motivacionais, são definidos no modelo, e caracterizam dez tipos:

\begin{tabular}{|c|c|}
\hline Tipos de valores & Metas motivacionais \\
\hline Poder & $\begin{array}{l}\text { Buscar prestígio e domínio sobre as pessoas e os recursos } \\
\text { materiais }\end{array}$ \\
\hline Realização & $\begin{array}{l}\text { Mostrar sucesso e competência de acordo com os padrões } \\
\text { sociais }\end{array}$ \\
\hline Hedonismo & Procurar prazer e gratificação sensual \\
\hline Estimulação & Procurar excitação, novidade e mudança \\
\hline Autodireção & Lutar pela independência no pensamento, na ação e nas escolhas \\
\hline Universalismos & Buscar compreensão, proteção da natureza e bem-estar de todos \\
\hline Benevolência & $\begin{array}{l}\text { Procurar o bem-estar das pessoas com quem tem relações } \\
\text { íntimas }\end{array}$ \\
\hline Tradi & Busca aceitação de padrões, humildade, devoção, gratidão \\
\hline Conformidade & Envolve cortesia, obediência, honradez, não prejudicar terceiros \\
\hline Segurança & $\begin{array}{l}\text { Envolve ordem social, limpeza, cuidado, harmonia social e } \\
\text { individual }\end{array}$ \\
\hline
\end{tabular}

Quadro 2 Escala de valores de Schwartz Fonte: Schwartz (1992).

\section{ASPECTOS METODOLÓGICOS}

A presente pesquisa, de natureza qualitativa, consistiu em entrevistas em profundidade com vinte alunos do terceiro ano do Ensino Médio de três escolas privadas situadas em Lavras (ao sul de Minas Gerais) com a finalidade de identificar a relação de valores desses alunos quando da escolha de uma Instituição de Ensino Superior (IES).

A coleta de dados do estudo se baseou em dois elementos: (i) amostragem não probabilística por conveniência, em que o pesquisador seleciona membros da população mais acessíveis para a realização da pesquisa (SCHIFFMAN; KANUK, 2000); (ii) técnica de 
encadeamento (laddering), a qual é mais recomendada para a elaboração das cadeias de meios e fins (GUTMAN, 1991). No presente estudo foi utilizada a laddering face-to-face.

As entrevistas foram conduzidas com o auxílio de um roteiro semiestruturado, sendo posteriormente gravadas, transcritas e tratadas por meio de análise de conteúdo, em que se agruparam sinônimos e se atribuíram códigos de resumo para cada sinônimo padronizado. Através desse procedimento, foi possível determinar quais elementos (atributos, consequências e valores) foram percebidos pelos consumidores e quais atributos conduziam a determinadas escalas de consequências e valores.

Segundo Vriens e Hofstede (2000), um número suficiente para identificar os valores está por volta de trinta respondentes. Entretanto, alguns estudos utilizam uma amostra significativamente menor (DIBLEY; BAKER, 2001; MANYINA; CRAWFORD, 2002). Na verdade, a literatura não é explícita quanto à quantidade recomendada de entrevistados para a realização da laddering. Veludo-de-Oliveira e Ikeda (2006a, p. 14) contribuem nesse sentido, ao afirmarem que um indicador do tamanho da amostra é a existência de um grau de saturação, ou seja, quando se percebe um nível de repetição das respostas. Por esse motivo, na presente pesquisa optou-se por vinte respondentes, pois foram percebidas concordâncias nas opiniões.

Após a realização de entrevistas em profundidade e de suas análises de conteúdo, foram identificados dez atributos, trinta consequências e onze valores, sendo que tais categorias foram construídas de acordo com a semelhança dos comentários em termos de significado.

Foi realizado um estudo das interrelações entre os 51 elementos identificados na análise de conteúdo, os quais são expressos no Mapa Hierárquico de Valores (MHV). Este consiste no objetivo final da técnica laddering. Através do MHV, pode-se mapear as relações existentes entre cada elemento (atributo, consequência e valor), verificando-se quais atributos conduzem a determinadas consequências e valores. Segundo Reynolds e Gutman (1988), pelo menos dois terços das representações devem ser visualizadas no mapa. Além disso, o mapa deve ser claro, de modo a facilitar a visualização das principais cadeias (MAKATOUNI; 2002; VILAS BOAS, 2005; VILAS BOAS et al., 2006). Para melhor visualização do mapa, as relações mais importantes foram filtradas com o estabelecimento de um ponto de corte equivalente a 4 . Isso significa que, para aparecer no mapa, uma relação entre dois elementos deveria ter sido citada um número de vezes igual ou superior ao ponto de corte, caso contrário seria descartada. Neste caso, foram representados 36\%, ou seja, 27 dos 51 elementos 
apareceram no MHV. No mapa estão indicados o número de vezes que os respondentes mencionaram cada elemento e sua representação em percentual.

Em auxílio ao uso da laddering, o software Mecanalyst, desenvolvido e utilizado por Naspeti e Zanoli (2004), colaborou para codificar os elementos, organizar os dados e construir a matriz de implicação e o Mapa Hierárquico de Valores.

\section{ANÁLISE E DISCUSSÃO DOS RESULTADOS}

O Mapa Hierárquico de Valores (MHV) permitiu identificar as relações existentes entre cada elemento (atributo, consequência e valor) dos alunos entrevistados, verificando quais atributos conduzem a determinadas consequências e valores. Após o ponto de corte, os 51 elementos identificados na análise de conteúdo - dez atributos, trinta consequências e onze valores - foram reduzidos, conforme exposto na figura 3.

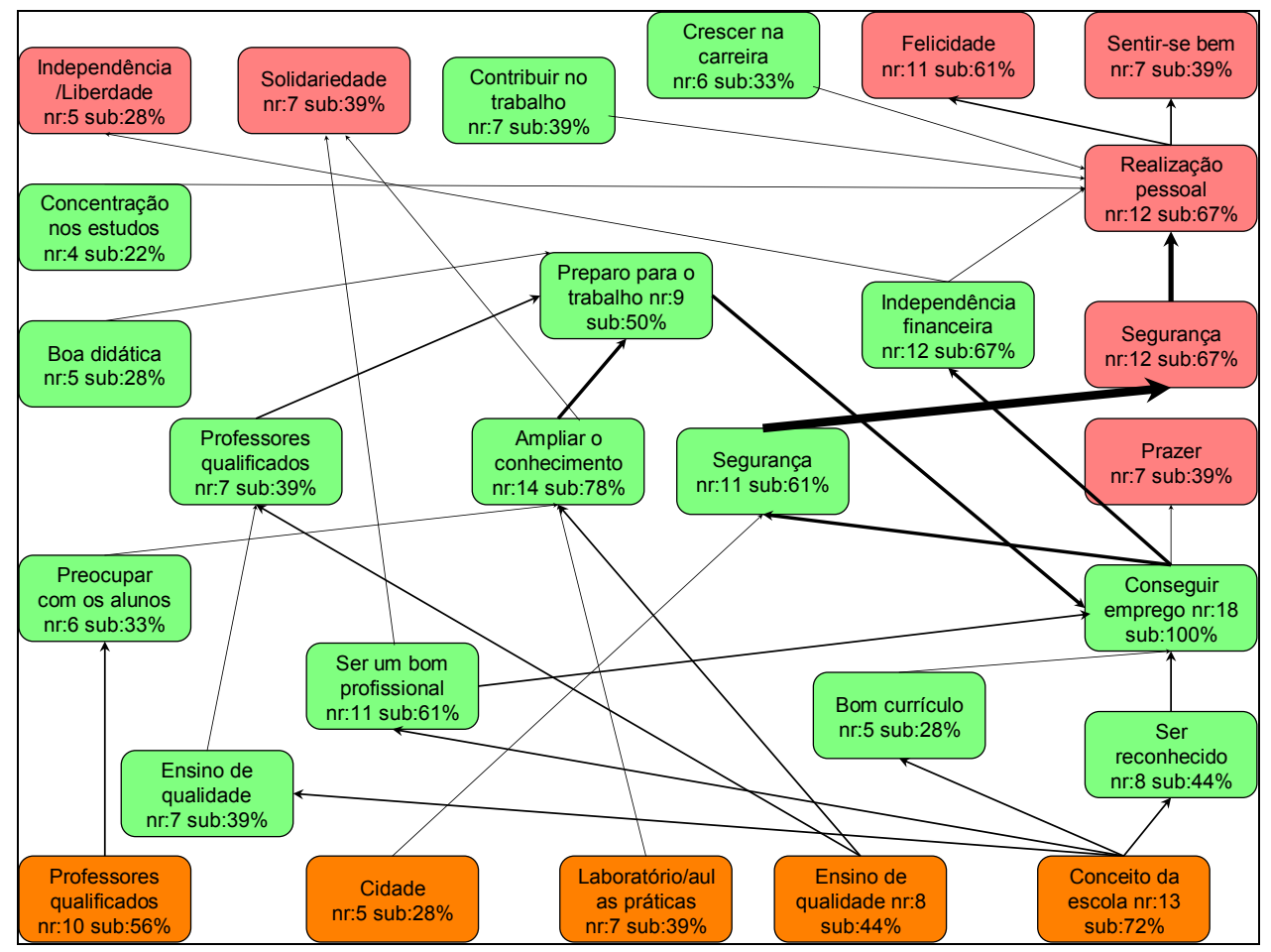

Figura 3 Mapa Hierárquico de Valores (MHV) dos alunos entrevistados Fonte: Elaborada pelos autores, com base nos dados da pesquisa.

Os principais atributos identificados no Mapa Hierárquico de Valores com os respectivos percentuais de entrevistados foram os seguintes (tabela 1): 


\begin{tabular}{|l|c|}
\hline \multicolumn{1}{|c|}{ Atributos } & \% Respondentes \\
\hline O bom conceito da IES diante da sociedade & $72 \%$ \\
\hline $\begin{array}{l}\text { A qualificação dos professores (mestrado, doutorado e pós- } \\
\text { doutorado) }\end{array}$ & $56 \%$ \\
\hline A qualidade do ensino da IES & $44 \%$ \\
\hline Existência de laboratórios e a ministração de aulas práticas & $39 \%$ \\
\hline $\begin{array}{l}\text { A cidade onde está localizada a IES (bem localizada, próximo } \\
\text { da família e acolhedora) }\end{array}$ & $28 \%$ \\
\hline
\end{tabular}

Tabela 1 - Principais atributos identificados no Mapa Hierárquico de Valores Fonte: Elaborada pelos autores, com base nos dados da pesquisa.

As consequências identificadas na análise de conteúdo foram as seguintes, com seus respectivos percentuais de respondentes (tabela 2):

\begin{tabular}{|l|l|}
\hline Consequências & \% Respondentes \\
\hline Facilidade para conseguir um emprego & $100 \%$ \\
\hline Possibilidade de ampliar o conhecimento & $78 \%$ \\
\hline Conseguir a independência financeira & $67 \%$ \\
\hline Ter mais segurança & $61 \%$ \\
\hline Ser um bom profissional & $61 \%$ \\
\hline Ter um melhor preparo para o trabalho & $50 \%$ \\
\hline Ser reconhecido na sociedade & $44 \%$ \\
\hline Ter a oportunidade de contribuir no trabalho & $39 \%$ \\
\hline Ter ensino de qualidade & $39 \%$ \\
\hline Ter professores qualificados & $39 \%$ \\
\hline Crescer na carreira & $33 \%$ \\
\hline Ter preocupação com os alunos & $33 \%$ \\
\hline Ter um bom currículo & $28 \%$ \\
\hline Ter uma boa didática & $28 \%$ \\
\hline Ter concentração nos estudos & $22 \%$ \\
\hline
\end{tabular}

Tabela 2 Principais consequências identificadas no Mapa Hierárquico de Valores Fonte: Elaborada pelos autores, com base nos dados da pesquisa.

Quanto aos valores, principal objeto de estudo dentro desta análise sobre a conexão entre esses três elementos (atributos, consequências e valores), os consumidores demonstraram sua preocupação em atingir os seguintes (tabela 3):

\begin{tabular}{|l|c|}
\hline \multicolumn{1}{|c|}{ Valores } & \% Respondentes \\
\hline Segurança & $67 \%$ \\
\hline Realização pessoal & $67 \%$ \\
\hline Felicidade & $61 \%$ \\
\hline Prazer & $39 \%$ \\
\hline Solidariedade & $39 \%$ \\
\hline Sentir-se bem & $39 \%$ \\
\hline Independência/liberdade & $28 \%$ \\
\hline
\end{tabular}

Tabela 3 - Principais valores identificados no Mapa Hierárquico de Valores Fonte: Elaborada pelos autores, com base nos dados da pesquisa. 
Conforme se observa no mapa, alguns atributos conduzem a mais de uma consequência e a mais de um valor. Por exemplo, o atributo "professores qualificados" leva às consequências "preocupar com os alunos", "ampliar o conhecimento", "preparo para o trabalho", "conseguir um emprego", "independência financeira” que, finalmente, leva ao nível de valor "realização pessoal". Neste caso, percebe-se que os alunos buscam por professores qualificados - que tenham mestrado, doutorado e pós-doutorado - e que se preocupem com eles, fazendo com que aqueles (os alunos) ampliem seu conhecimento, preparando-se para o trabalho de modo que consigam um emprego, estabilidade financeira e, assim, a realização pessoal.

Percebe-se, pela maior espessura das ligações, que alguns elementos foram considerados dominantes na percepção dos entrevistados. Um exemplo desse fato é a ligação entre as consequências: (i) "conseguir um emprego" e "segurança"; (ii) "preparo para o trabalho" e "conseguir um emprego"; (iii) "conseguir um emprego" e "independência financeira" etc. Por meio dessas ligações verifica-se que um número significativo dos entrevistados acreditam que conseguir um emprego traz segurança, que o preparo para o trabalho ajuda a conseguir um emprego e que este leva à independência financeira.

Observa-se nas respostas uma forte presença de questões essencialmente psicológicas, que derivam da subjetividade e dos desafios da modernidade, em que o importante não é só possuir um emprego, mas sim um emprego que leve os sujeitos à independência financeira. Esses argumentos considerados dominantes são explicados por suas consequências e atributos.

Entretanto, uma análise do Mapa Hierárquico de Valores também permite identificar alguns elementos da cadeia de meios e fins, tais como:

- Atributos concretos: Ao se analisar os aspectos físicos e funcionais envolvidos na avaliação por parte dos alunos, mesmo que pouco significativos com as questões relacionadas, observa-se a preocupação com: (i) bibliotecas amplas e com acervo atualizado; (ii) laboratórios especializados e bem equipados para a ministração de aulas práticas; (iii) número reduzido de alunos nas salas; (iv) maior número de candidatos por vaga; (v) diversidade de opções de cursos de graduação e pósgraduação ofertados pela IES; (vi) programa de colocação dos egressos no mercado; (vii) o posicionamento da IES no ranking do ENADE; (viii) preços acessíveis das mensalidades ou IES federalizadas.

- Atributos abstratos: A filosofia educacional implantada, a proximidade da família e morar em uma cidade acolhedora e segura são atributos de cunho subjetivo, uma vez que dependem diretamente de conceitos anteriormente interiorizados nas pessoas. 
- Consequências funcionais: Uma preocupação muito presente nos dias atuais diz respeito à colocação profissional; logo, como consequência dos atributos citados anteriormente, tem-se a compatibilização entre trabalho e lazer. Outro ponto importante é quanto à gratuidade do ensino superior, consequência direta do fato de a instituição ser federalizada.

- Consequências psicossociais: As consequências observadas serão divididas em quatro grandes campos: Família, Educação, Sociedade e Trabalho.

$\checkmark$ No campo Família, os alunos demonstraram ter necessidade do apoio da família, já que, para parte da amostra investigada, o laço familiar é muito forte e necessário. O apoio da família é considerado, portanto, um fator preponderante;

$\checkmark$ Quanto às questões relacionadas à Educação, os entrevistados mencionaram a necessidade de as aulas serem concentradas em um mesmo lugar, proporcionando o acesso às outras instalações da instituição. Professores qualificados são entendidos como consequência de escolas mais preparadas, da mesma forma que o ensino de qualidade deriva desse mesmo atributo. Um bom currículo é tido como consequência de uma filosofia educacional adequada. A possibilidade de pós-graduação mostra a preocupação desses alunos com seu futuro acadêmico e profissional. $O$ interesse dos professores pelos alunos, pela preparação para o mercado de trabalho, por laboratórios/aulas práticas e por uma escola sem perda de tempo mostra um novo perfil de aluno, que se preocupa intensamente com seu tempo, sua formação e seu futuro. Ex.: Os alunos entrevistados entendem que um "corpo docente qualificado" pode apoiá-los na construção do saber. Evidentemente existe a preocupação com a qualificação formal, ou seja, "professores que tenham mestrado, doutorado e pós-doutorado...", contudo, manifesta-se por parte dos alunos que a didática, o modo como são passadas as informações e a preocupação com os discentes são pontos importantes. Isso pode ser verificado em trechos retirados das entrevistas, tais como: "[...] um professor que se preocupa com os alunos, quer saber se o aluno realmente está aprendendo e se envolve com ele [...]", "Professores que sabem, mas não somente para eles [...] Sabem passar a matéria [...]", “[...] quando os professores sabem passar a matéria a gente entende. Aprende de verdade [...]";

$\checkmark$ Ao tratar de Sociedade, os entrevistados valorizam: (i) a segurança das cidades; (ii) o reconhecimento da sociedade; (iii) ter um bom relacionamento e amizade. Estas certamente são características que compõe a estrutura social de uma comunidade, ou seja, os entrevistados gostariam de encontrar nas escolas algo semelhante a uma comunidade segura, acolhedora e amiga;

$\checkmark$ No campo Trabalho observa-se uma série de preocupações por parte dos alunos, envolvendo um melhor preparo para o trabalho, a facilidade para conseguir um emprego, a possibilidade de crescimento profissional e até mesmo a oportunidade de contribuir com a sociedade como um todo.

- Valores instrumentais (externos): Contribuir com o próximo é um anseio que faz parte das respostas dos entrevistados. Isso mostra algum grau de consciência da responsabilidade e equanimidade social por parte dos entrevistados. Este é um valor que se encontra voltado para o tema da responsabilidade social, o qual deve fazer parte da missão das IES.

- Valores terminais (internos): Sentir-se bem, ser feliz e ter prazer no que se faz mostra quanto os indivíduos estão preocupados em conciliar trabalho de qualidade 
com prazer no seu cotidiano. A independência dos indivíduos foi bastante ressaltada, precisando ser valorizada e respeitada por parte das IES.

\section{CONCLUSÃO}

Diante das questões discutidas neste trabalho, é importante considerar que o estudo do comportamento do cliente/consumidor se faz relevante para a aplicação adequada de ações relacionadas ao perfil das Instituições de Ensino Superior, bem como às formas de atendimento que apoiem a compra e o consumo dos seus serviços.

Diante do universo das respostas pode-se inferir que os alunos pesquisados têm muito claros seus propósitos, objetivos e, consequentemente, seus sonhos. Eles almejam IES que tenham as seguintes características: o reconhecimento da sociedade; professores qualificados, com boa didática e dispostos a apoiar os alunos; um ensino de alto nível; aulas práticas em laboratórios especializados; bibliotecas amplas e com acervo atualizado; número reduzido de alunos nas salas; maior número de candidatos por vaga, como uma expressão do reconhecimento; diversidade de opções de cursos de graduação, para facilitar a sua escolha profissional; oferta de cursos de pós-graduação lato e stricto sensu, para facilitar a progressão nos estudos; programa de colocação dos egressos no mercado; preços acessíveis das mensalidades ou IES federalizadas; ambiente escolar com características de uma comunidade segura, acolhedora e amiga; dentre outros. Além disso, é necessário que a IES seja localizada em uma cidade que inspire segurança ao cliente.

Tais atributos levam a diversas consequências desejáveis aos consumidores dos serviços educacionais no ensino superior, tais como: ter a possibilidade de ampliação do conhecimento como estudante; ter um bom currículo, aumentando as chances de conseguir um emprego de qualidade; ter maior segurança no exercício da profissão; ser um profissional reconhecido e respeitado na sociedade; ter a oportunidade de crescer na carreira profissional; conquistar a tão sonhada independência financeira; dentre outras.

Tais atributos e consequências se encontram ligados a diversos valores expressos nas escalas dos vários autores citados. Os principais valores dessa escala encontrados no estudo foram: prazer, segurança, realização pessoal, felicidade, solidariedade, independência/liberdade, poder contribuir. Todos esses valores se encontram presentes nas escalas de valores Rokeach (1973), Kahle, Beatty e Homer (1986) e Schwartz (1992).

Assim, do ponto de vista estratégico e de mercado, é necessário que as Instituições de Ensino Superior estejam preparadas para atender aos anseios desses jovens que estão se 
preparando para o ingresso em suas fileiras. Paralelamente, verifica-se que a comunidade como um todo deve saber acolher e estabelecer vínculos com os estudantes de ensino superior, fazendo com que estes desempenhem um papel importante para a sociedade, aplicando os conhecimentos adquiridos em sua formação para o bem comum. Um outro vértice dessa discussão é o apoio da família na decisão e no suporte aos jovens no período de formação, devido aos fortes laços presentes nessa relação. Quando se tem esses três pontos de apoio articulados e em cooperação, cria-se o ambiente desejado pelos estudantes para o seu ingresso no ensino superior. Portanto, deve-se buscar mecanismos que proporcionem essa interação, para que, no futuro, esse tipo de decisão por parte dos alunos seja mais sedimentada e condizente com as expectativas geradas, evitando evasões, desinteresse e, consequentemente, profissionais mal formados e infelizes.

Neste ambiente de avanço da mercantilização da educação, somente as IES bem posicionadas, com valor agregado, governança compatível com o novo contexto, foco na oferta de serviços de qualidade e capacidade de atuar em rede poderão sobreviver. As IES que não se adequarem a essas condições terão de gerenciar crises de demanda e crises financeiras ou irão desaparecer, pois terão dificuldades de se estabelecerem no mercado educacional, altamente competitivo.

Assim, cabe aos gestores das IES planejar, implementar, orientar, monitorar, avaliar, discutir e buscar alternativas para as demandas institucionais. Para tanto, é importante implementar objetivos estratégicos e metas com foco nos resultados (eficiência, efetividade, qualidade dos serviços e impacto), na opção dos clientes e nas parcerias (escutar os clientes e fazer parcerias), na capacidade para explorar as novas fontes de recursos (buscar novas fontes, vender serviços), na publicação dos resultados (accountability) e nos acordos estratégicos e de corresponsabilidade.

Finalmente, ressalta-se que este é um tema complexo, que necessita de outras reflexões acuradas e contextualizadas. Assim, os autores reconhecem que as considerações feitas neste trabalho tocam apenas a "superfície do iceberg", não esgotando o tema. São necessários novos estudos com a profundidade e acuidade que o tema merece, incluindo pesquisas com maior abrangência numérica e em outras localidades. Podem ser desenvolvidos trabalhos que se utilizem de métodos quantitativos e, assim, possibilitem uma amostra de maior volume com uso de questionários estruturados, de modo a testar as proposições sobre os valores aqui alcançados. Tomando como base as percepções definidas por este trabalho, 
outros estudos podem ser realizados em busca da definição de estratégias de segmentação e posicionamento dentro do mercado do ensino superior.

\section{REFERÊNCIAS}

ANDRADE FILHO, J. C. Mudança na política educacional e posicionamento estratégico: Estudo comparativo de casos em Instituições de Ensino Superior. 2000. 296 f. Dissertação (Mestrado em Administração) - Universidade Federal do Paraná, Curitiba, 2000.

BAKER, S.; THOMPSON, K. E.; ENGELKEN, J. Mapping the values driving organic food choice: Germany vs the UK. European Journal of Marketing, v. 38 n. 8, p. 995-1012, 2004.

BORENSTEIN, C. R. Alternativas estratégicas para Instituições de Ensino Superior em ambientes competitivos. Florianópolis: UFSC/PPGEP, 2008.

BRUNNER, J. J.; URIBE, D. Mercados universitarios: el nuevo escenario de la educación superior. Santiago: Ediciones Universidad Diego Portales, 2007.

CUNHA, L. A. Desenvolvimento desigual e combinado no ensino superior: Estado e mercado. Revista Educação e Sociedade, Campinas, v. 25, n. 88, p. 795-817, out. 2004.

DIBLEY, A.; BAKER, S. Uncovering the links between brand choice and personal values among young British and Spanish girls. Journal of Consumer Behavior, v. 1, n. 1, p. 77-93, jun. 2001.

HUFFMAN, C.; RATNESHWAR, S.; MICK, D. G. The why of consumption: contemporary perspectives on consumer motives, goals and desires. London: Routledge, 2000.

GUTMAN, J. A. Means-end chain model based on consumer categorization processes. Journal of Marketing, v.46, n. 1, p.60-72, Spring, 1982.

GUTMAN, J. Exploring the nature of linkages between consequences and values. Journal of Business Research, v. 22, n. 2, p. 143-148, 1991.

IKEDA, A. A.; VELUDO-DE-OLIVEIRA, T. M. Usos e limitações do Método Laddering. Revista de Administração Mackenzie, São Paulo, v. 5, n. 1, p. 197-222, 2004.

KAHLE, L. R.; BEATTY, S. E.; HOMER, P. Alternative measurement approaches to consumer values: the list of values (LOV) and values and life style (VALS). Journal of Consumer Research, Chicago, v. 13, n. 3, p. 405-409, dez. 1986.

KOTLER, P.; FOX, K. Marketing estratégico para instituições educacionais. São Paulo: Atlas, 1994.

MAKATOUNI, A. What motivates consumers to buy organic food in the UK? Results from a qualitative study. British Food Journal, Bradford, v. 104, n. 3-5, p. 345-352, 2002. 
MANYINA, S.; CRAWFORD, I. Determining linkages between consumer choice in a social context and the consumer's value: a means-end approach. Journal of Consumer Behavior, v. 2, n. 1, p. 54-70, set. 2002.

INEP - INSTITUTO NACIONAL DE ESTUDOS E PESQUISAS EDUCACIONAIS.

Resumo Técnico do Censo da Educação Superior 2009. Disponível em:

$<$ http://portal.inep.gov.br/web/censo-da-educacao-superior/resumos-tecnicos $>$. Acesso em: 22 set. 2011.

NASPETTI, S.; ZANOLI, R. Do consumers care about where they buy organic products? A means-end study with evidence from Italian data. In: BAOURAKIS, G. (Ed.). Marketing trends for organic food in the $21^{\text {st }}$ century. 1. ed. Cingapura: World Scientific, 2004, v. 3, p. 238-255.

OECD - ORGANIZAÇÃO PARA A COOPERAÇÃO E DESENVOLVIMENTO ECONÔMICO. Tertiary education for the knowledge society. OECD thematic review of tertiary education: synthesis report. Abr. 2008.

OLSON, J.; REYNOLDS, T. Understanding consumers cognitive structures: implications for advertising strategy. In: PERCY, L.; WOODSIDE, A. (Eds.). Advertising and consumer psychology. Lexington: Lexington Books, 1983. p. 77-90.

PIMENTA, M. L.; VILAS BOAS, L. H. B. Percepções de consumidores de alimentos orgânicos na cidade de Uberlândia na perspectiva de valores: uma aplicação da laddering e cadeia de meios e fins. IN: ENCONTRO DE MARKETING DA ANPAD, 3, 2008, Curitiba. Anais..., Curitiba: ANPAD, 2008.

PIÑOL, S. T. A imagem das Instituições de Ensino Superior junto às empresas de seleção e recrutamento. Florianópolis: NUPEAU/CPGA/UFSC, 2008.

REYNOLDS, T. J.; GUTMAN, J. Laddering theory, method, analysis, and interpretation. Journal of Advertising Research, v. 28, n. 1, p. 11-31, 1988.

ROKEACH, M. J. The nature of human value. New York: Free Press, 1973.

SCHWARTZ, S. H. Universals in the content and structure of values: theory and empirical tests in 20 countries. Advances in Experimental Social Psychology, New York, v. 25, p. 1$65,1992$.

SCHIFFMAN, L.; KANUK, L. Comportamento do consumidor. 6. ed. São Paulo: LTC, 2000 .

SERRALVO, F. A.; IGNACIO, C. P. O comportamento do consumidor de produtos alimentícios: um estudo exploratório sobre a importância das marcas líderes. In: SEMINÁRIOS EM ADMINISTRAÇÃO DA FEA-USP, 7, 2004, São Paulo. Anais.... São Paulo: SEMEAD, 2004. 
SGUISSARDI, V. Modelo de expansão da Educação Superior no Brasil: predomínio privado/mercantil e desafios para a regulação e a formação universitária. Revista Educação e Sociedade, Campinas, v. 29, n. 105, p. 991-1022, set./dez. 2008.

SILVA, E. D.; ANASTÁCIO, M. R. Mudança no ambiente político-legal e formulação estratégica: um estudo de caso da Universidade Regional de Blumenau (FURB). In: ENCONTRO NACACIONAL DE ENGENHARIA DE PRODUÇÃO, 25, 2005, Porto Alegre. Anais... Porto Alegre: ABEPRO, 2005.

TAMAYO, A. Contribuições ao estudo dos valores pessoais, laborais e organizacionais. Psicologia: teoria e pesquisa, Brasília, v. 23, n. especial, p. 17-24, 2007.

VALETTE-FLORENCE, P.; RAPACCHI, B. Improvements in means-end-chains analysis: using graph theory and correspondence analysis. Journal of Advertising Research, v. 31, n. 1, p. 30-45, fev.-mar. 1991.

VELUDO-DE-OLIVEIRA, T. M.; IKEDA, A. A. O conceito de valor para o cliente: definições e implicações gerenciais em marketing. Gestão Organizacional, Recife, v. 3, n. 1, p. 40-52, jan./abr. 2005.

VELUDO-DE-OLIVEIRA, T. M.; CAMPOMAR, A. A. Laddering in the practice of marketing research: barriers and solution. Qualitative Market Research, v. 9, n. 3, p. 297$306,2006$.

VELUDO-DE-OLIVEIRA, T. M.; IKEDA, A. A. Valor em serviços educacionais. RAEeletrônica, São Paulo, v. 5, n. 2, art. 12, jul./dez. 2006 a.

VELUDO-DE-OLIVEIRA, T. M.; IKEDA, A. A. A teoria de meios-fim: uma aplicação em marketing educacional. FACES Revista de Administração, Belo Horizonte, v. 5, n. 1, p.1125, jan./abr. 2006b.

VILAS BOAS, L. H. B. Comportamento do consumidor de produtos orgânicos: uma análise na perspectiva da teoria da cadeia de meios e fins. 2005. $222 \mathrm{f}$. Tese (Doutorado em Administração) - Universidade Federal de Lavras, Lavras, 2005.

VILAS BOAS, L. H. B. et al. Comportamento do consumidor de produtos orgânicos: uma aplicação da teoria da cadeia de meios e fins. In: ENCONTRO DE MARKETING DA ANPAD, 2, 2006, Rio de Janeiro. Anais... Rio de Janeiro: ANPAD, 2006.

VILAS BOAS, L. H. B. Perspectivas de segmentação para o mercado de produtos orgânicos com base na estrutura de valores. In: ENCONTRO NACIONAL DE PÓS-GRADUAÇÃO E PESQUISA EM ADMINISTRAÇÃO, 31, 2007, Rio de Janeiro. Anais... Rio de Janeiro: ANPAD, 2007.

VRIES, M.; HOFSTEDE, F. T. Linking attributes, benefits and consumer values. Journal of Marketing Research, v. 12, n. 3, p. 4-10, 2000.

WOODRUFF, R. B. Customer value: the next source of competitive advantage. Journal of the Academy of Marketing Science, v. 25, n. 2, p. 139-154, 1997. 